\title{
Espécies vegetais indicadas na odontologia
}

\author{
Francielda Q. Oliveira*, Bárbara Gobira, Carolina Guimarães, Jamylle Batista, Mariana \\ Barreto, Mônica Souza
}

\author{
Laboratório de Farmacobotânica, Centro Universitário Newton Paiva, Av. Silva Lobo 1730, \\ 30480-230, Belo Horizonte, Minas Gerais, Brasil
}

\begin{abstract}
RESUMO: Foi realizada uma revisão bibliográfica sobre plantas medicinais indicadas para afecções odontológicas, incluindo livros, artigos e sites científicos e populares. Os dados foram compilados em uma tabela contendo informações como nome científico, popular, família, parte utilizada e forma farmacêutica. Foram encontradas 132 espécies, distribuídas em 52 Famílias Botânicas citadas como úteis no tratamento de afecções odontológicas. As espécies mais citadas de acordo com a bibliografia consultada foram Punica granatum L. (10 citações), Althaea officinalis L.(8), Salvia officinalis L. (8), Calendula officinalis L.(8), Malva sylvestris L (7), Plantago major L. (6). O conjunto destes resultados deve permitir um perfil de espécies para uso em odontologia e contribuir para o direcionamento de pesquisas nesta área, culminando com o desenvolvimento de fitoterápicos de qualidade e validados para uso odontológico, bem como permitindo a divulgação destes estudos para a população e profissionais afins.
\end{abstract}

Unitermos: Plantas medicinais, afecções odontológicas, revisão bibliográfica.

\begin{abstract}
Plants species indicated in odontology". A bibliographical review on medicinal plants indicated for odontological disease was carried through, including books, articles and scientific and popular sites. The data had been compiled in a Table with information such as plants scientific and popular names, family, used part and pharmaceutical form. A total of 132 species, distributed in 52 Botanical Families useful in the treatment of odontological afeccion had been found. The most cited species in the bibliography consulted were Punica granatum L. (10 citations), Althaea officinalis L.(8), Salvia officinalis L. (8), Calendula officinalis L.(8), Malva sylvestris L (7), Plantago major L. (6). The set of these results must allow a profile of species for use in odontology and contribute for the aiming of research in this area, culminating with the development of herbal medicines of quality and validated for odontological use, as well as allowing to the spreading of these studies for the population and similar professionals.
\end{abstract}

Keyword: Medicinal plants, odontological diseases, bibliographical review.

\section{INTRODUÇÃO}

As afecções odontológicas podem ser evidenciadas por sintomas característicos de diversas etiologias, dentre elas as mais comuns são as cáries, a gengivite, a periodontite, estomatite aftosa e herpes simples (Regezi; Sciubba, 2000; Newman, 2004).

A cárie dentária é uma infecção microbiana dos tecidos calcificados dos dentes, um processo dinâmico caracterizado por perda mineral, que ocorre sempre que o equilíbrio entre a superfície dentária e o fluido da placa é alterado, como resultado da metabolização de carboidratos fermentáveis pelos microrganismos (Buischi, 2000).

A gengivite, inflamação dos tecidos gengivais, pode ocorrer em forma aguda, subaguda ou crônica. Esta pode aparecer devido a fatores locais, tais como a presença de microrganismos e impactação de alimentos ou devido a fatores sistêmicos como distúrbios de nutrição e características hereditárias. Além disso, a gengivite pode preceder e evoluir para a periodontite de maior gravidade, que envolve não só a gengiva, mas também o osso alveolar, o cemento e o ligamento periodontal, levando à perda de dentes (Regezi; Sciubba, 2000).

Há problemas relacionados também com a cicatrização após extração de um dente. Nesses casos, o sangue que preenche o alvéolo deveria coagular naturalmente. Porém, se esse coágulo for deslocado, a cicatrização pode ser bastante retardada e dolorosa devido à vasodilatação e mobilização dos leucócitos na área afetada (Newman, 2004).

Na estomatite aftosa há o desenvolvimento de ulcerações recidivantes dolorosas, solitárias ou múltiplas na mucosa bucal. Herpes simples é uma doença infecciosa comum, causada pelo vírus do herpes simples (HSV). Existem dois tipos, mas é o tipo 1 que afeta geralmente a região da boca (Regezi; Sciubba, 2000).

Algumas dessas afecções vêm sendo tratadas com a fitoterapia. Espécies como Cravo da Índia, Romã, 
Malva, Tanchagem, Amoreira, Sálvia, Camomila, entre outras, são indicadas nos casos de gengivite, abscesso na boca, inflamação e aftas (Torres et al., 2000; Blumenthal et al., 2000; Franco; Fontana, 2002; Brandão et al., 2003; Barreto et al., 2005; Brandão et al., 2006; Silva et al., 2006; Agra et al., 2007).

As plantas têm sido, desde a antiguidade, um recurso ao alcance do ser humano. O homem encontrou nas chamadas plantas medicinais, virtudes que foram transmitidas de geração a geração. Essas plantas têm significado um marco na história do desenvolvimento de nações. Até nas sociedades mais industrializadas, o uso de vegetais in natura pela população vem cada vez mais se intensificando (Miguel; Miguel, 1999).

Com base no uso e conhecimento popular, o importante crescimento mundial da fitoterapia dentro de programas preventivos e curativos tem estimulado a avaliação da atividade de diferentes extratos de plantas para o controle do biofilme dental, bem como de outras afecções bucais (Buffon et al., 2001). O biofilme dental parece ser o fator determinante da cárie e doença periodontal, justificando desta maneira, a utilização de medidas para o seu controle.

Inúmeros trabalhos vêm sendo realizados para avaliação de espécies vegetais na Odontologia, como Equinacea purpurea, Copaifera multijuga, Lippia sidoides, Stryphnodendron barbatiman, entre outras (Ferreira, 1996; Bandeira, 1999; Couto, 2000; Melo Júnior et al., 2000; Paixão, 2002; Vendola, 2004; Feres et al., 2005).

O Brasil possui grande potencial para o desenvolvimento da Fitoterapia aplicada inclusive à Odontologia, já que apresenta a maior diversidade vegetal do mundo, ampla sociodiversidade, com o uso de plantas medicinais vinculado ao conhecimento tradicional e tecnologia para validar cientificamente este conhecimento (Martins, 2000; Albuquerque; Hanazaki, 2006).

Em levantamento realizado pelo Ministério da Saúde no ano de 2005 (Ministério da Saúde 2005,) em todos os municípios brasileiros, verificou-se que a fitoterapia está presente em 116 municípios, contemplando 22 unidades federadas (Brasil, 2004). Atualmente a Fitoterapia faz parte do Sistema Único de Saúde, sendo possível a sua inclusão médica e odontológica (Brasil, 2006; Silva et al., 2006).

Devido à grande utilização das plantas medicinais em diferentes aplicações terapêuticas, este trabalho teve como objetivo fazer uma revisão bibliográfica sobre espécies indicadas para o tratamento de afecções odontológicas, de maneira a contribuir para triagem e direcionamento de pesquisas de novos fitoterápicos eficazes e validados para estas patologias.

\section{MATERIAL E MÉTODOS}

Para o desenvolvimento dessa revisão foram pesquisados livros, sites e artigos científicos, na busca de indicações de plantas medicinais na odontologia em afecções como cáries, estomatites, gengivites, periodontites e outras. Para cada espécie vegetal buscouse informações, tais como: nome científico e popular, família a que pertence, a parte utilizada, assim como forma farmacêutica e indicações terapêuticas. Uma tabela foi construída para registro do número de citações e identificação da bibliografia em que cada espécie foi citada. No caso de citações apenas de nomes populares foram pesquisadas as prováveis espécies conhecidas por tal nome e seu nomes científicos. Para verificação dos binômios, autores corretos e Família, a fim de evitar possíveis confusões botânicas foi utilizado o banco de dados do Missouri Botanical Garden (MOBOT, 2005). Foram selecionadas as famílias com maior número de espécies citadas, bem como as espécies com maiores números de citação, para as quais foi feita uma revisão na biliografia. As bibliografias foram enumeradas em ordem cronológica de consulta.

\section{RESULTADOS E DISCUSSÃO}

Foram encontradas 132 espécies, distribuídas em 52 Famílias Botânicas, citadas como úteis no tratamento de afecções odontológicas. A Tabela 1 contém dados sobre as espécies medicinais indicadas na bibliografia consultada para o tratamento destas afecções (Tabela 1).

As famílias com os maiores números de espécies citadas foram Asteraceae (16 espécies), Lamiaceae (10), Myrtaceae (8), Rosaceae (8) e Fabaceae (7). Foi possível notar o maior número de citações para espécies dentro da família Asteraceae, sendo esta a maior família botânica entre as angiospermas e muito pesquisada devido ao grande potencial medicinal de suas espécies. A família Asteraceae foi descrita inicialmente como Compositae por Dietrich Giseke. Essa família compreende 1528 gêneros, com aproximadamente 22750 espécies encontradas em todo o planeta (Di Stasi; Hiruma-Lima, 2002).

A família Lamiaceae apresentou um número expressivo de espécies. Esta família inclui cerca de 252 gêneros, nos quais se distribuem 6700 espécies. Além da importância do ponto de vista medicinal, esta família também é fonte de espécies com grande valor como condimentos, alimentos e na indústria de perfumes e cosméticos. Dentre os inúmeros gêneros, destacam-se Mentha, Ocimum e Plectranthus, gênero também citado nesta revisão (Di Stasi; Hiruma-Lima, 2002).

As plantas medicinais mais indicadas, de acordo com a bibliografia consultada foram Punica granatum L. (10 citações), Althaea officinalis L. (8), Salvia officinalis L. (8), Calendula officinalis L. (8), Malva sylvestris L (7) e Plantago major L. (6). 
Punica granatum, espécie pertencente à Família Punicaceae, e mais conhecida como romã, tem apresentado ação bactericida e bacteriostática sobre bactérias Gram-positivas e Gram-negativas constituintes do biofilme dental (Pereira, 2004; Pereira et al., 2006). $\mathrm{O}$ autor estudou a ação antibacteriana do extrato hidroalcoólico da casca de romã, frente a diferentes bactérias. Esta ação antibacteriana foi ainda comparada à atividade antibacteriana da clorexidina. Foi verificado que todas as linhagens bacterianas se mostraram sensíveis ao extrato ativo de romã. A espécie vem sendo empregada também para periodontites (Sastravaha et al., 2005), como antioxidante (Ricci et al., 2006), e em estomatites (Vasconcelos et al., 2003).

A espécie Althaea officinalis, conhecida popularmente como malvavísco, pertencente à família Malvaceae vem sendo testada quanto a atividade antibacteriana e tem demonstrado eficácia contra bactérias periodontopatogênicas (Iauk et al., 2003).

A infusão preparada com a Sálvia, Salvia officinalis L. vem sendo estudada quanto à sua atividade antioxidante (Lima et al., 2005), antimicrobiana (Barreto et al., 2005) e hipoglicemiante (Barbosa-Filho et al., 2005; Funke; Melzig, 2006).

A Calendula officinalis é uma espécie exótica empregada na cicatrização de feridas com ação antiinflamatória e antibacteriana (Blumenthal et al., 2000; Shultz et al., 2002; Sartori et al., 2003; Falcão et al., 2005). Na Odontologia vem sendo testada no controle de crescimento de bactérias em biofilme dental (Buffon et al., 2001), contra bactérias periodontopatogênicas (Iauk et al., 2003), entre outros.

A Malva (Malva sylvestris) foi uma das plantas mais citadas nesta pesquisa. Esta espécie é conhecida por suas propriedades antiinflamatórias, antimicrobianas, presença de mucilagens, taninos, óleos essenciais, glicolipídios e flavonóides e vem sendo testada no controle de crescimento de bactérias presentes no biofilme dental (Torres et al., 2000; Buffon et al., 2001) e citada em diferentes levantamentos etnobotânicos (Guarrera, 2005; Mendes et al., 2006).

Apesar da Tanchagem não ter tido um número expressivo de citações, é uma espécie com importância na terapêutica e vem sendo submetida a ensaios de atividade farmacológica, inclusive de atividade sobre o crescimento de bactérias (Farias et al., 2002) envolvidas na formação do biofilme dental (Buffon et al., 2001), bem como tem sido citada em trabalhos de levantamentos etnobotânicos. Em estudo realizado na região sul de Cuiabá, percebeu-se a grande utilização do chá das folhas da Tanchagem, Plantago major, para se fazer gargarejos principalmente. Esta espécie possui indicações para amigdalite, estomatite, faringite, e de uso externo para úlceras e feridas, sob a forma de emplastro podendo agir como cicatrizante (Bieski, 2005).

As formas farmacêuticas mais citadas para utilização das espécies foram decocto, infusão, gargarejo e chá. Outras também foram indicadas como emplastro, maceração, tintura e creme tópico.

\section{CONCLUSÃO}

A fitoterapia proporciona alternativas de tratamento para afecções odontológicas. No estudo realizado, observou-se que Punica granatum L., Althaea officinalis L., Salvia officinalis L., Calendula officinalis L., Malva sylvestris L e Plantago major L. foram as mais citadas nas bibliografias pesquisadas. Todas estas espécies têm sido amplamente empregadas na medicina popular e vêm sendo submetidas a alguns ensaios na área de Odontologia. Embora o emprego dessas plantas seja difundido, ainda faltam estudos científicos que comprovem o uso para a maioria dessas espécies nas afecções odontológicas.

Desta forma, o conjunto destes resultados deve permitir um perfil de espécies para uso em odontologia e contribuir para o direcionamento de pesquisas nesta área, culminando com o desenvolvimento de fitoterápicos de qualidade e validados para uso odontológico, bem como permitindo a divulgação destes estudos para a população e profissionais afins.

\section{AGRADECIMENTOS}

Ao Odontólogo Marco Antônio Hudson de Souza pelas contribuições pessoais e bibliográficas na elaboração deste trabalho.

\section{REFERÊNCIAS}

Agência de Jornalismo Científico 2005. Disponível em http:// www.academika.ufrn.br, acesso em Agosto/2005).

Agra MF, França PF, Barbosa-Filho JM 2007. Synopsis of the plants known as medicinal and poisonous in Northeast of Brazil. Rev Bras Farmacogn 17: 114140.

Albuquerque UP, Hanazaki N 2006. As pesquisas etnodirigidas na descoberta de novos fármacos de interesse médico e farmacêutico: fragilidades e pespectivas. Rev Bras Farmacogn 16(Supl.): 678-689.

Balducci-Roslind EO, Silvério KG, Malagoli DM 1999. Processo de reparo em feridas de extração dentária em camundongos tratados com o complexo Symphytum officinale e Calendula officinallis. Rev Odontol Univ São Paulo 13: 181-187.

Bandeira MFCL 1999. Estudo farmacológico preliminar de Copaifera multijuga (óleo de copaíba). J Bras Clin Estet Odontol 3: 39-41.

Barbosa-Filho JM, Vasconcelos THC, Alencar AA, Batista LM, Oliveira RAG, Guedes DN, Falcão HS, Moura MD, Diniz MFFM, Modesto-Filho J 2005. Plants and their active constituents from South, Central, and North America with hypoglycemic activity. Rev Bras Farmacogn 15: 392-413.

Barreto LV, Costa Feitosa AMS, Araújo JT, Chagas KF, Costa K 2005. Acción antimicrobiana in vitro de 


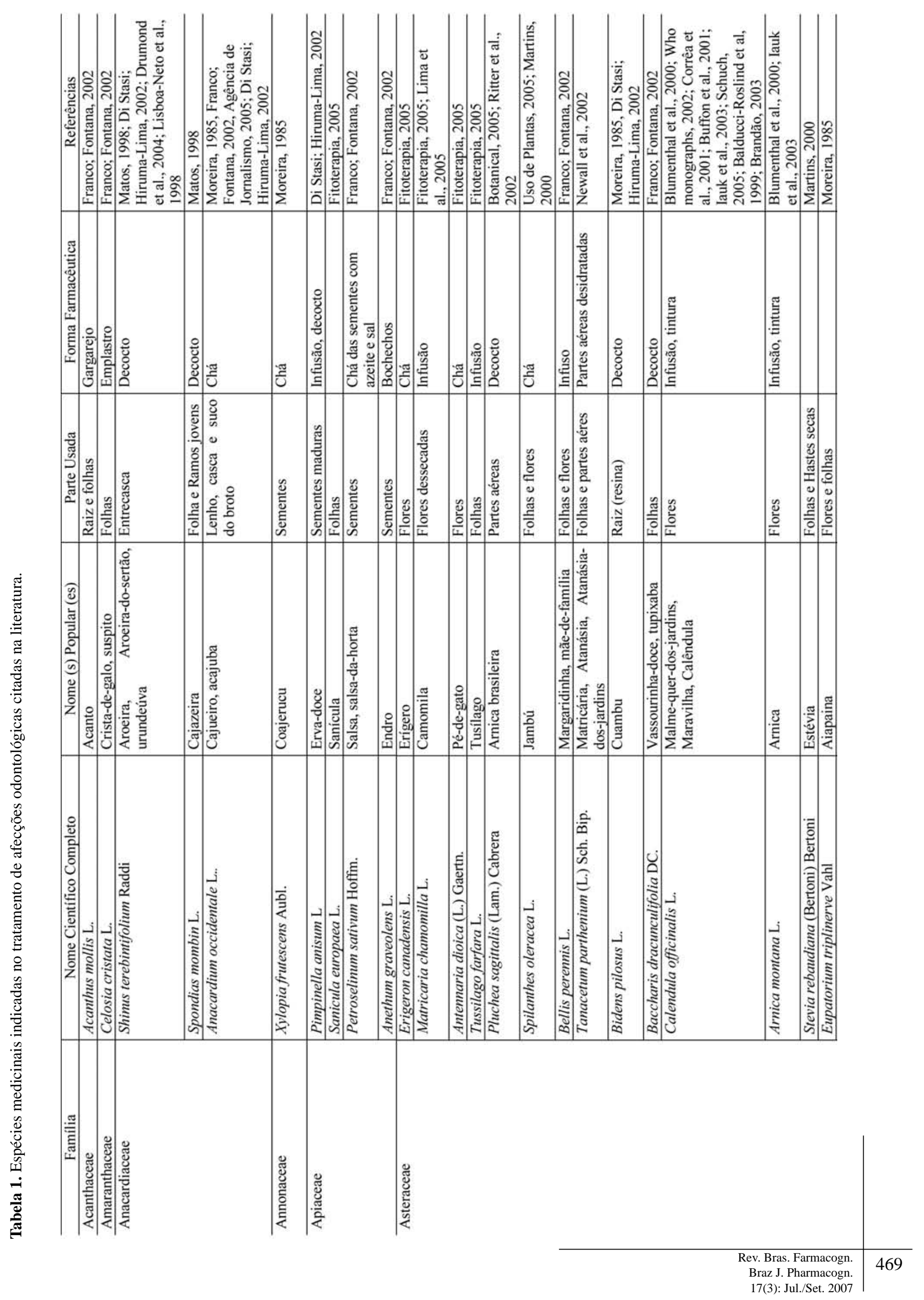



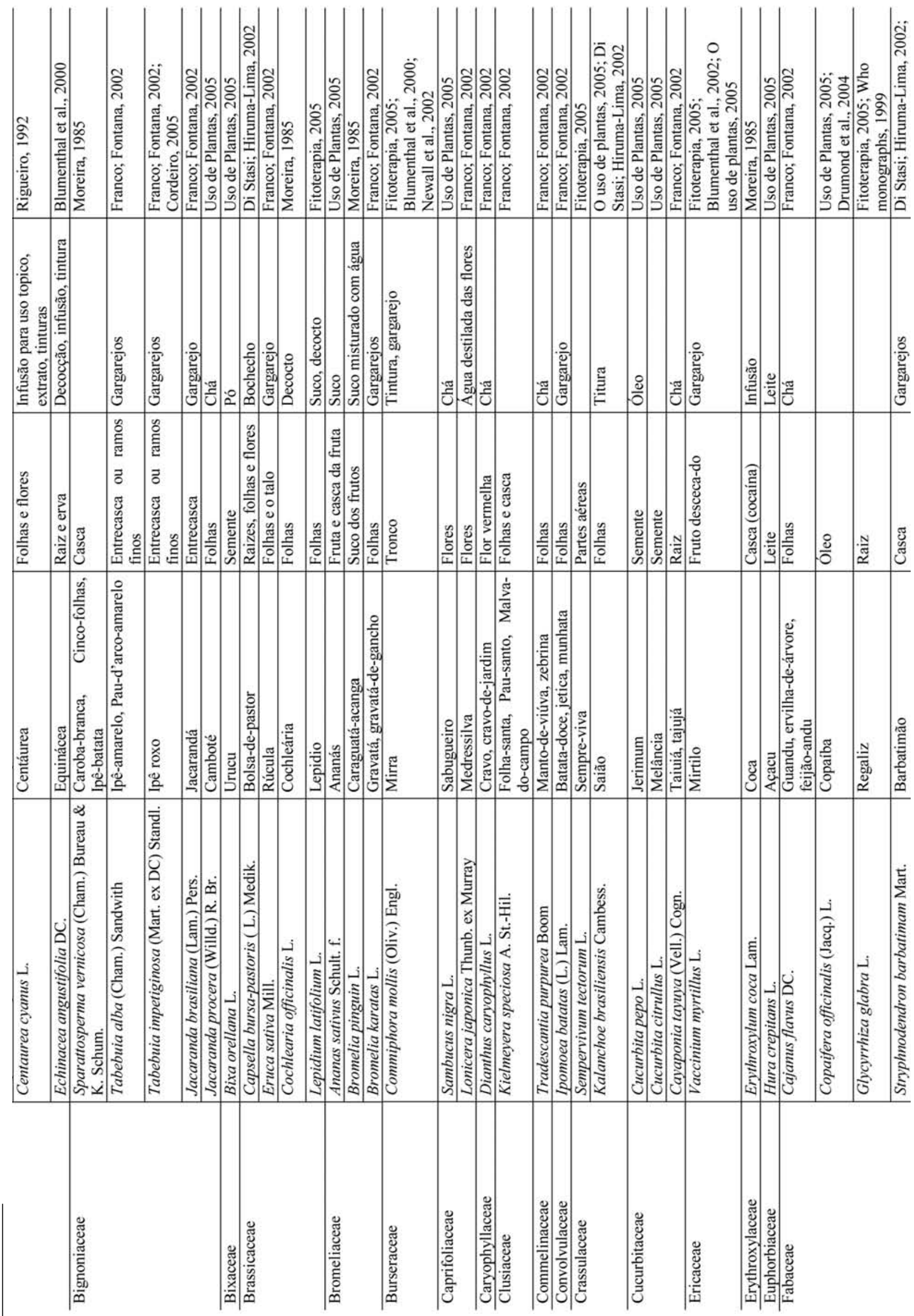

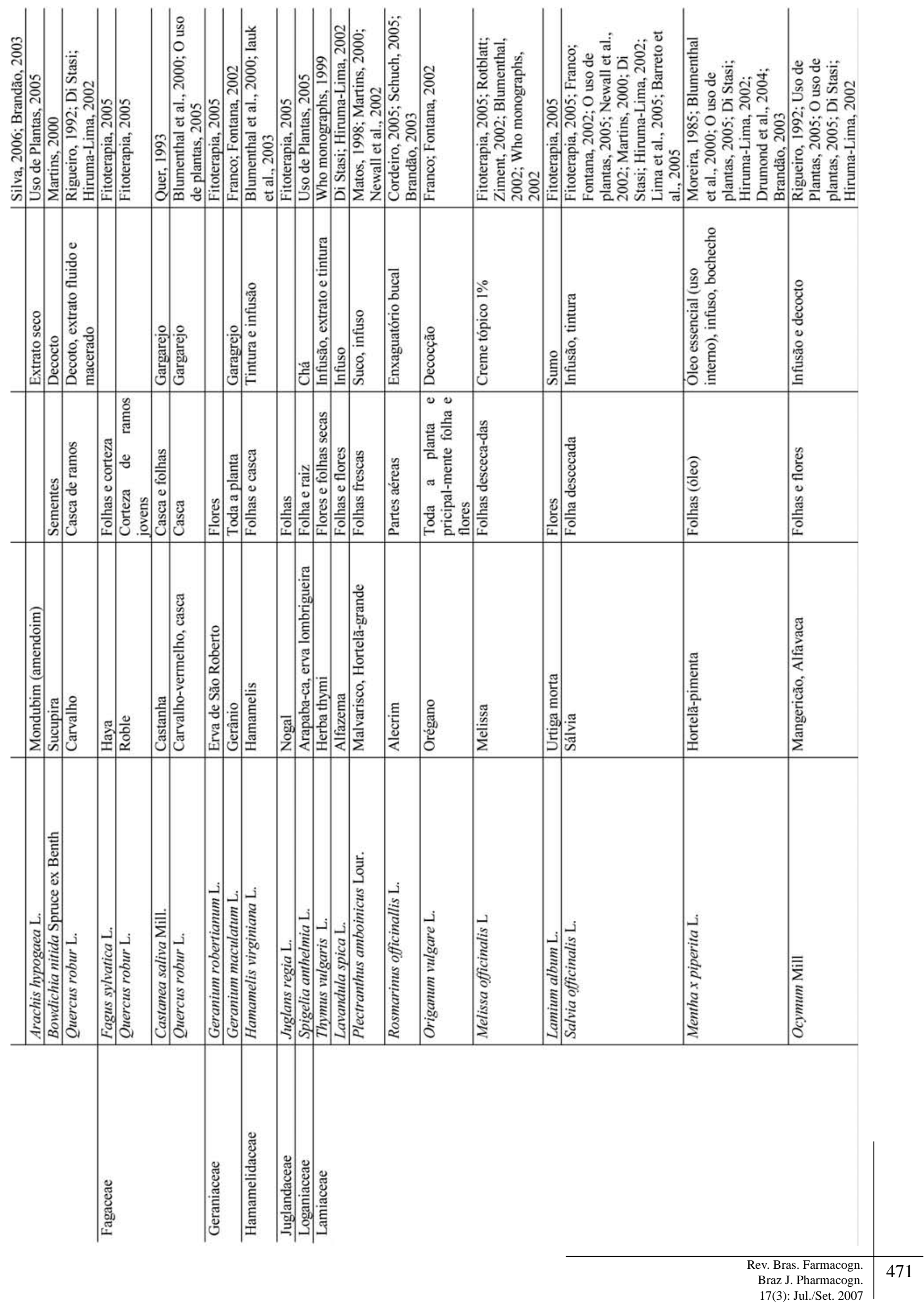


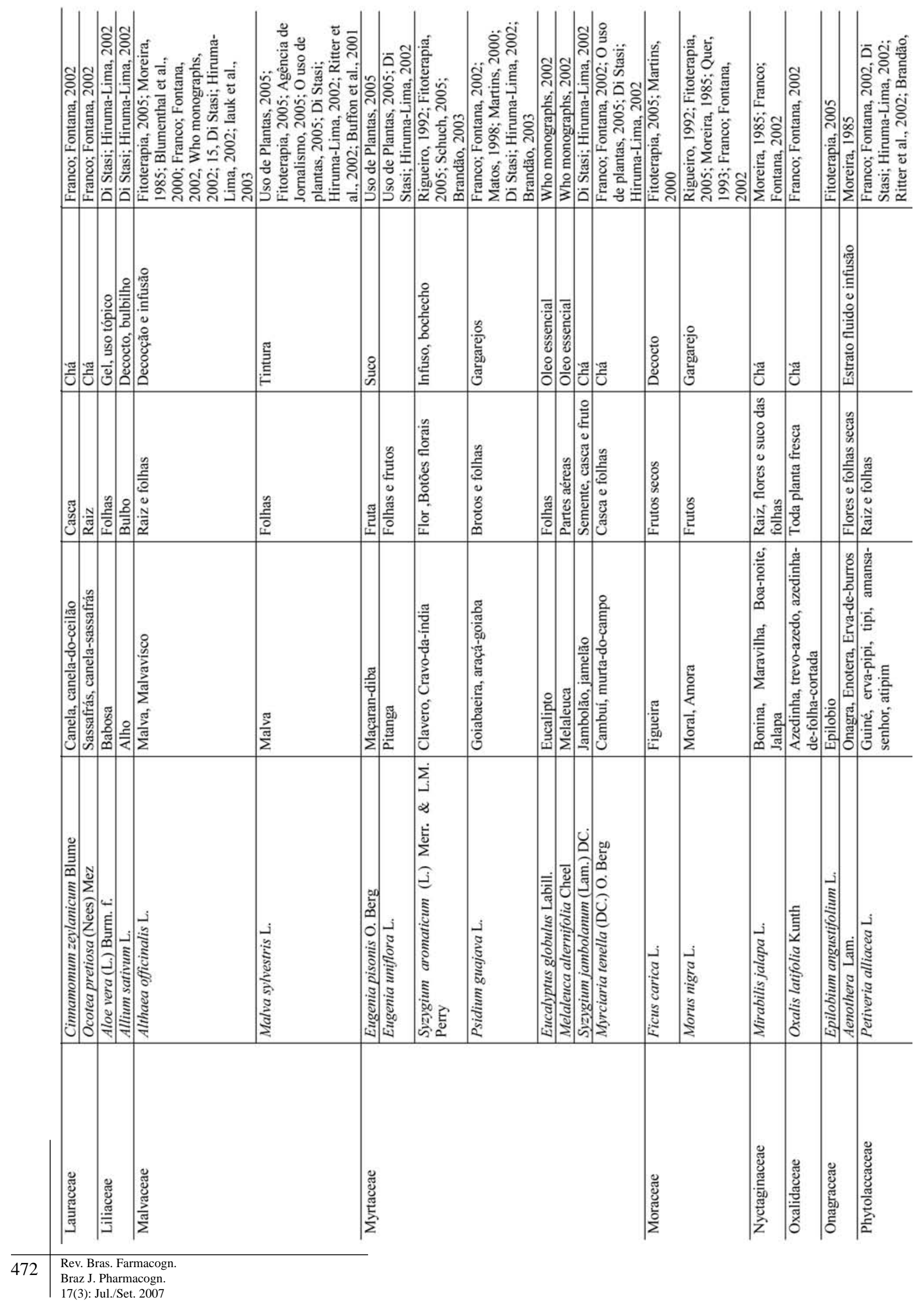






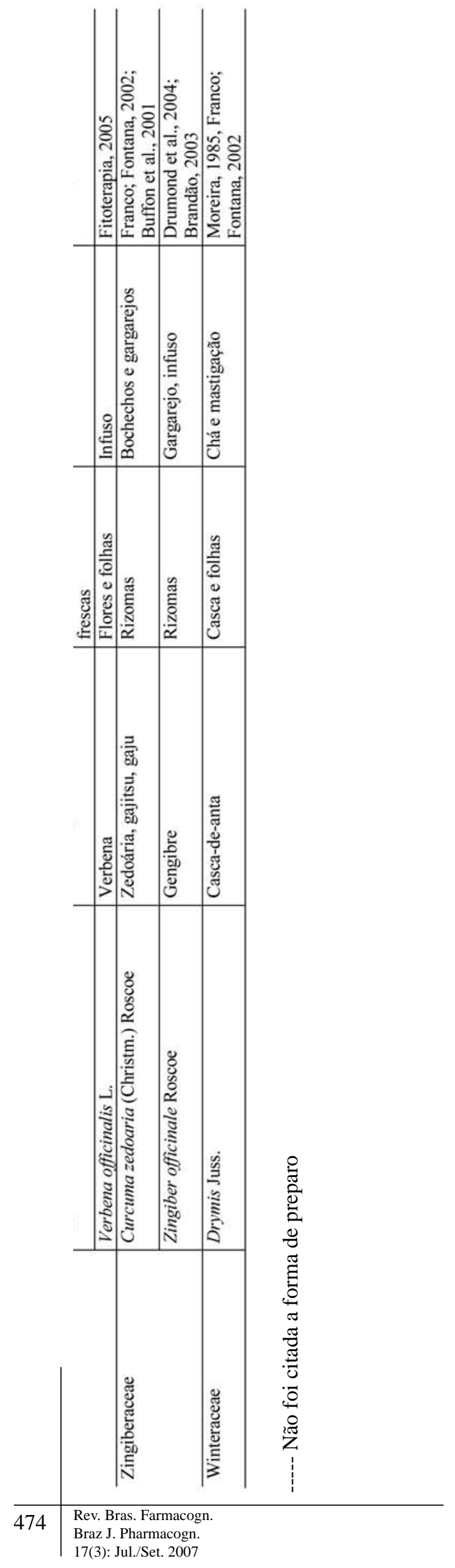


dentífricos conteniendo fitoterápicos. Avances en Odontoestomatología. 21: 195-201.

Bieski IGC 2005. Plantas medicinais e aromáticas no sistema único de saúde da região sul de Cuiabá-MT. Disponível em http://www.esalq.usp.br, acesso em Setembro/2005.

Blumenthal M, Goldberg A, Brinckmann J 2000. Herbal Medicine - Expanded Commission and Monographs. American Botanical Council.

Botanical-online 2005. Disponível em http://www.botanicalonline.com , acesso em Setembro/2005.

Brandão MGL, Cosenza GP, Moreira RA, Monte-Mor RLM 2006. Medicinal plants and other botanical products from the Brazilian Official Pharmacopoeia. Rev Bras Farmacogn 16: 408-420.

Brandão MGL, Bandeira CC, Andrade GTB 2003. Circuito das plantas medicinais - guia informativo 2003. Belo Horizonte: Gráfica O Lutador, 68p.

Brandão MGL (Org.) 2003. Plantas medicinais \& fitoterapia. BH: Faculdade de Farmácia da UFMG, 140p.

Brasil 2006. Ministério da Saúde. Agência Nacional de Vigilância Sanitária. Portaria $n^{\circ}$ 971, de 3 de maio de 2006.

Brasil 2004. Ministério da Saúde. Agência Nacional de Vigilância Sanitária Resolução da Diretoria Colegiada RDC n.48, de 16 de Março de 2004.

Buffon MCM, Lima MLC, Galarda I, Cogo L 2001. Avaliação da eficácia dos extratos de Malva sylvestris, Calendula officinalis, Plantago major e Curcuma zedoarea no controle do crescimento das bactérias da placa dentária. Estudo “in vitro”. Revista Visão Acadêmica 2: 31-38.

Buischi YP 2000. Promoção de saúde bucal na clinica odontológica.São Paulo: Editora Artes Médicas.

Cordeiro CHG 2005. Atividade biológica de gel dentifrício e enxagüatório bucal contendo extratos vegetais. $98 \mathrm{f}$. Dissertação (Mestrado em Ciências Farmacêuticas) Faculdade de Ciências Farmacêuticas, Universidade Estadual Paulista, Araraquara, 2005. Disponível em http://www.biblioteca.unesp.br/bibliotecadigital, acesso em Junho de 2006.

Corrêa AD, Batista RS, Quintas LEM 2001. Plantas Medicinais: do cultivo à terapêutica. Petrópolis: Vozes.

Couto GBL 2000. Biocompatibilidade do extrato hidroalcoólico da Lippia sidoides Cham (Verbenaceae). Rev Cons Reg Odontol Pernambuco.3: 83-90.

Di Stasi LC, Hiruma-Lima CA 2002. Plantas medicinais na Amazônia e na Mata Atlântica. 2.ed. São Paul: Editora Unesp.

Drumond MRS, Castro RD, Almeida RVD, Pereira MSV, Padilha WWN 2004. Estudo Comparativo in vitro da atividade antimicrobiana de produtos fitoterápicos. Pesquisa Brasileira em Odontopediatria e Clínica Integrada. 4: 33-38.

Falcão HS, Lima IO, Santos VL, Dantas HF, Diniz MFFM, Barbosa-Filho JM, Batista LM 2005. Review of the plants with anti-inflammatory activity studied in Brazil. Rev Bras Farmacogn 15: 381-391.

Freitas AG, Costa V, Farias ET, Lima MCA, Sousa IA Ximenes EA 2002. Atividade antiestafilocócica do Plantago major L. Rev Bras Farmacogn 12(Supl.): 64-65.
Feres M, Figueiredo LC, Barreto IM, Coelho MH, Araujo MW, Cortelli SC 2005. In vitro antimicrobial activity of plant extracts and propolis in saliva samples of healthy and periodontally-involved subjects. $J$ Int Acad Periodontol 7: 90-96.

Ferreira B. 1996. Fitoterapia: plante essa idéia. Rev ABO Nac 4: 2-5 [36].

Fitoterapia 2005. Disponível em http://www.fitoterapia.net, acesso em Agosto/2005).

Franco IJ, Fontana VL 2002. Ervas \& plantas: a medicina dos simples. 7.ed. Erexim-RS: Editora Edelbra.

Guarrera PM 2005. Traditional phytotherapy in Central Italy. Fitoterapia 76: 1-25.

Iauk L, Lo Bue AM, Milazzo I, Rapisarda A, Blandino G 2003. Antibacterial activity of medicinal plant extracts against periodontopathic bacteria. Phytother Res 17: 599-604.

Lima CF, Andrade PB, Seabra RM, Fernandes-Ferreira M, Pereira-Wilson C 2005. The drinking of a Salvia officinalis infusion improves liver antioxidant status in mice and rats. $J$ Ethnopharmacol 97: 383-389.

Lisboa Neto JA, Machado JL, Melo Junior EJM, Raposo MJ 1998. Avaliaçäo do efeito cicatrizante da aroeira (Schinus terebinthifolius) e do mastruço (Chenopodium ambrosioides) em feridas de extraçäo dental em ratos: estudo histológico. Rev $A B O$ Nac 6:173-176.

Martins ER 2000. Plantas medicinais. Viçosa: UFV.

Matos FJA 1998. Farmácias vivas: sistema de utilização de plantas medicinais projetado para pequenas comunidades. 3.ed. Fortaleza: UFC.

Melo Júnior EJM, Raposo MJ, Sant'Ana, AEG, Lisboa Neto JÁ, Diniz MFA. 2000. Estudo de plantas medicinais com atividade antimicrobiana sobre microrganismos presentes na alveolite. Revista ABO Nac 8: 4-9.

Mendes BG, Machado MJ, Falkenberg M 2006. Triagem de glicolipídios em plantas medicinais. Rev Bras Farmacogn 16: 568-575.

Miguel MD, Miguel OG 1999. Desenvolvimento de fitoterápicos. São Paulo: Editora Robe.

Ministério da Saúde 2005. Disponível em http://www.amhb. org.br, acesso em Setembro/2005).

MOBOT 2005. Missouri Botanical Garden. Banco de dados. Disponível em http://www.mobot.org, acesso em Setembro/2005.

Moreira F 1985. Plantas que curam - cuide de sua saúde através da natureza. Editora Hemus, 256p.

Newall CA, Anderson LA, Phillipson JD 2002. Plantas medicinais: guia para profissional de saúde. São Paulo: Editora Premier.

Newman MG 2004. Periodontia clínica. Rio de Janeiro: Editora Guanabara Koogan.

O uso de plantas medicinais 2005. Disponível em http:// www.drplantinha.hpg.ig.com.br, acesso em Setembro/2005.

Paixão CCB 2002. Uso de plantas medicinais em pacientes portadores de afecções bucais. Odontologia Clínicocientífica 1: 1-4.

Pereira JV, Pereira MSV, Sampaio FC, Sampaio MCC, Alves PM, Araújo CRF, Higino JS 2006. Efeito antibacteriano e antiaderente in vitro do extrato da Punica granatum Linn. sobre microrganismos do biofi lme dental. Rev Bras Farmacogn 16: 88-93. 
Pereira JB 2004. atividade antimicrobiana do extrato hidroalcoólico da Punica granatum Linn. sobre microrganismos formadores de placa bacteriana. Pesquisa Brasileira em Odontopediatria e Clínica Integrada 4: 265.

Quer PF 1993. Plantas medicinales - el diocórides renovado. Editorial Labor.

Regezi JÁ, Sciubba JJ 2000. Patologia bucal: correlações clinicopatológicas. 3.ed. Rio de Janeiro : Editora Guanabara Koogan.

Ricci D, Giamperi L, Bucchini A, Fraternale D 2006. Antioxidant activity of Punica granatum fruits. Fitoterapia 77: 310-312.

Rigueiro MP 1992. Plantas que curam - Manual ilustrado de plantas medicinais. 6.ed. Editora Paulus, 183p.

Ritter MR, Sobierajski GR, Schenkel EP, Mentz LA 2002. Plantas usadas como medicinais no município de Ipê, RS,Brasil. Revi Bras Farmacogn 12: 51-62.

Rotblatt M, Ziment I 2002. Herbal medicine - evidence-based. Philadelphia: Hanley \& Belfus [6].

Sartori LR, Ferreira MS, Perazzo FF, Mandalho-Lima L, Carvalho JCT 2003. Atividade antiinflamatória do granulado de Calendula officinalis L. e Matricaria recutita L. Rev Bras Farmacogn 13 (Supl. 1): 17-19.

Sastravaha G,Gassmann G, Sangtherapitikul P, Grimm WD 2005. Adjunctive periodontal treatment with Centella asiatica and Punica granatum extracts in supportive periodontal therapy. J Int Acad Periodontol 7: 7079.

Schuch TCH 2005. Cravo-da-índia reduz a placa bacteriana. Disponível em http://www.maringa.com/saude/ placa_bacteriana.php, acesso em Junho de 2006.

Shultz V, Hansel R, Tyler VE 2002. Fitoterapia Racional. São Paulo: Editora Manole. 386p.

Silva AMR 2006. Plantas medicinais na odontologia: Barbatimão. Jornal CRO/MG 169. Disponível em http://www.cromg.org.br, acesso em Junho de 2006.

Silva MIG, Gondim APS, Nunes IFS, Sousa FCF 2006. Utilização de fitoterápicos nas unidades básicas de atenção à saúde da família no município de Maracanaú (CE). Rev Bras Farmacogn 16: 455-462.

Torres CRG, Cubo CH, Anido AA, Rodrigues JR 2000. Agentes antimicrobianos e seu potencial de uso na odontologia. Rev Fac Odontol São José dos Campos 3: 43-52.

Uso de plantas medicinais em afecções odontológicasm2005. Disponível em http://www.apcd.org.br, acesso em Agosto/2005).

Vasconcelos LC, Sampaio MC, Sampaio FC, Higino JS 2003. Use of Punica granatum as an antifungal agent against candidosis associated with denture stomatitis. Mycoses 46: 192-196.

Vendola MCC 2004. Equinacea purpurea na odontologia. Tecnicas Esteticas 1: 3-12.

Who monographs on selected medicinal plants $1999.1 \mathrm{v}$. Geneva: World Health Organization.

Who monographs on selected medicinal plants 2002. 2v. Geneva: World Health Organization.

Yarza O 2001. Plantas que curam \& Plantas que matam. Editora Garnier, 2v. 